\title{
BODY AS ECHOES: CYBER ARCHIVING OF DAZU ROCK CARVINGS
}

\author{
Chen Wu-Wei \\ IMA Program, Shanghai NYU, 1555 Century Ave, Pudong Xinqu, Shanghai Shi, China, 200122 - wc54@nyu.edu
}

\section{Commission II}

Keywords: Digital Heritage, Digital Sculpting, STEM Education, Interactive Info-Motion Design, Dazu Rock Carvings

\begin{abstract}
:
"Body As Echoes: Cyber Archiving of Dazu Rock Carvings (BAE project in short)" strives to explore the tangible/intangible aspects of digital heritage conservation. Aiming at Dazu Rock Carvings - World Heritage Site of Sichuan Province, BAE project utilizes photogrammetry and digital sculpting technique to investigate digital narrative of cultural heritage conservation. It further provides collaborative opportunities to conduct the high-resolution site survey for scholars and institutions at local authorities. For preserving and making sustainable of the tangible cultural heritage at Dazu Rock Carvings, BAE project cyber-archives the selected niches and the caves at Dazu, and transform them into high-resolution, three-dimensional models. For extending the established results and making the digital resources available to broader audiences, BAE project will further develop interactive info-motion interface and apply the knowledge of digital heritage from BAE project to STEM education. BAE project expects to bridge the platform for archeology, computer graphics, and interactive info-motion design. Digital sculpting, projection mapping, interactive info-motion and VR will be the core techniques to explore the narrative of digital heritage conservation. For further protecting, educating and consolidating "building dwelling thinking" through digital heritage preservation, BAE project helps to preserve the digital humanity, and reach out to museum staffs and academia. By the joint effort of global institutions and local authorities, BAE project will also help to foster and enhance the mutual understanding through intercultural collaborations.
\end{abstract}

\section{HISTORY OF WORK ON THE PROJECT TO DATE}

During the six years (2011-2016) of professor position, The author delivers cultural heritage related topics in the studio classes such as digital sculpting and visual programming in the U.S. university. The author shares insights of the 3-D Mandala deployed in the Lecture Hall of To-Ji Temple in Kyoto and helps students from scratch to portray the deities with complex forms by digital sculpting tools. [Figure 1] Besides the duty of teaching, the author also collaborates with cultural organizations in Hong Kong to cyber-archive the cultural objects from Peshawar (e.g., narrative relief and deities of Bodhisattva, Maitreya, and Shakyamuni), and study the iconography of religious deities from different geolocations in Asia. [Figure $2 / 2.1]$

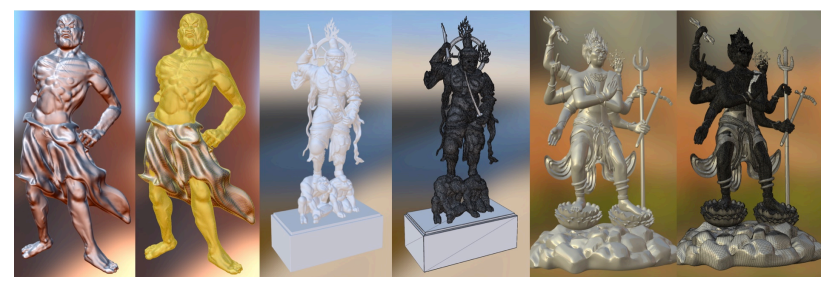

Figure 1. Deities at the temples of Kyoto and Nara sculpted by digital tools.

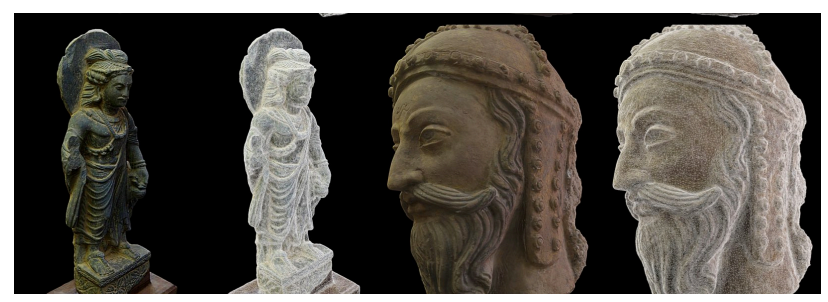

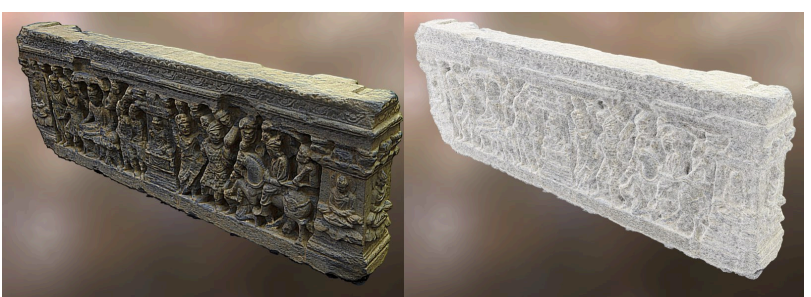

Figure 2/2.1: Photogrammetry documentation of Gandhārastyle carved grey schist Shakyamuni, Bodhisattva (gilt), Standing Maitreya and narrative relief.

Earlier in 2016, the author conducted the field research by personal efforts at the World Heritage Site of Sichuan Province - Dazu Rock Carvings. Selected Esoteric deities (Bodhisattva, Ksitigarbha, and Peacock Radiant Wisdom King) [Figure 3] are digitally documented and transformed into the 3-D models. To further develop the interactive contents, digital museum, STEM education, and info-motion design for Dazu Rock Carvings, the author collaborates with Dazu Rock Carving Institute in Sichuan Province and works together with collaborative partners from Southwest University of Nationalities. The full supports from local authorities enables the author to contribute to the academic network of Dazu School. Further collaborations will continue to facilitate the conservation efforts by innovative technologies.

\section{METAMORPHOSIS OF THE SUTRA AND THE DIGITAL NARRATIVE}

In Buddhism, Buddha is free from reincarnation and karma. Bodhisattva, on the other hand, stays with the sentient beings and leads them to the Pure Land. Hence the diverse expressions and gestures are depicted on the Buddha and Bodhisattva. [Figure 4] The Mikaeri Amida (Amitabha Looking Back) deity at Zenrin-Ji in Kyoto for example, "looks back to the sentient beings with mercy, and interprets the attitudes of thinking back 
on his own position, waiting for the people behind and leading them to the way of salvation together." $\left[{ }^{1}\right]$ [Figure 5]
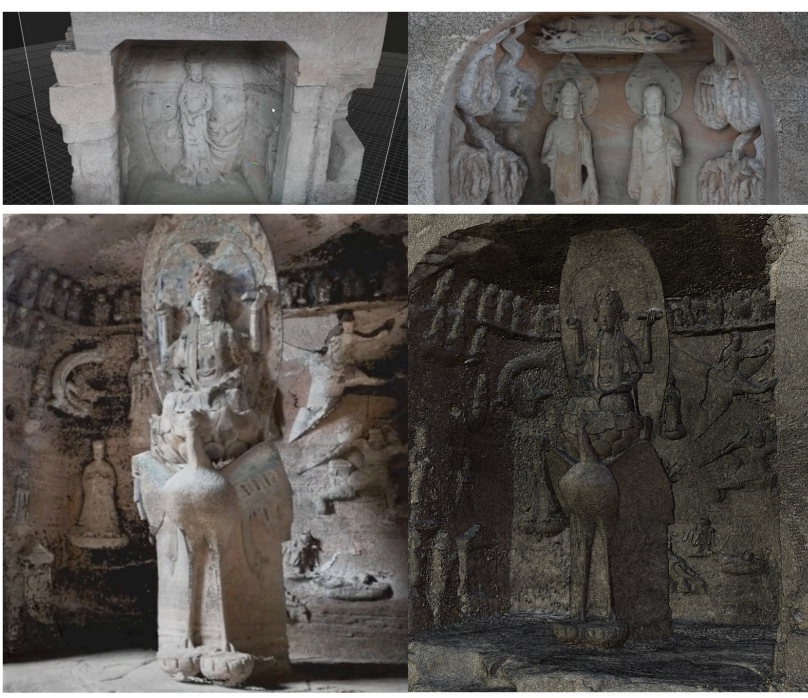

Figure 3: Digital documentations of the Esoteric deities (Bodhisattva, Ksitigarbha, and Peacock Radiant Wisdom King) at Dazu Rock Carving in Sichuan Province, China.

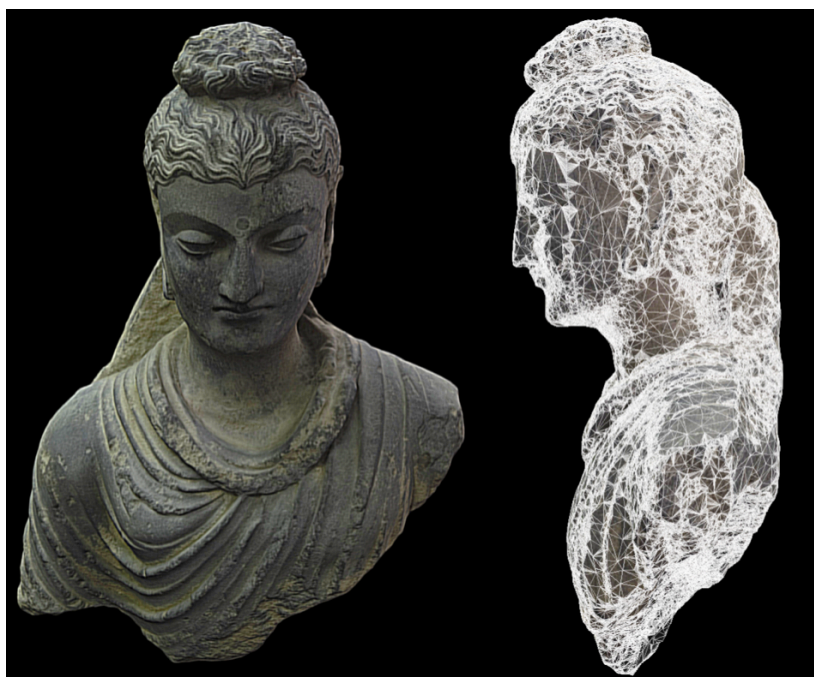

Figure 4: Shakyamuni deity carved grey schist of the ancient region of Gandhara circa 2nd century. Cyber-archive by Photogrammetry.

Similar scenarios can be found on the deity of Peacock Radiant Wisdom King in Dazu Rock Carvings. This deity, which is akin to the one in the cave No. 155 at Beishan area, "sits in padmasana cross-legged lotus posture on the lotus throne placed on the back of a peacock." $\left.{ }^{2}\right]$ The tail of the peacock extends all the way up to the ceiling as the halo, and works similarly as the central pillar to hold the structure of the cave. Most of the heavenly kings are portrayed with wrathful expressions as the alternative representations of the Bodhisattva to defeat the demons. The faces of the Peacock Radiant Wisdom Kings at
Beishan (Cave No.115) and Shimenshan (Cave No.8) [Figure 6] are rather gentle and merciful as Bodhisattva.

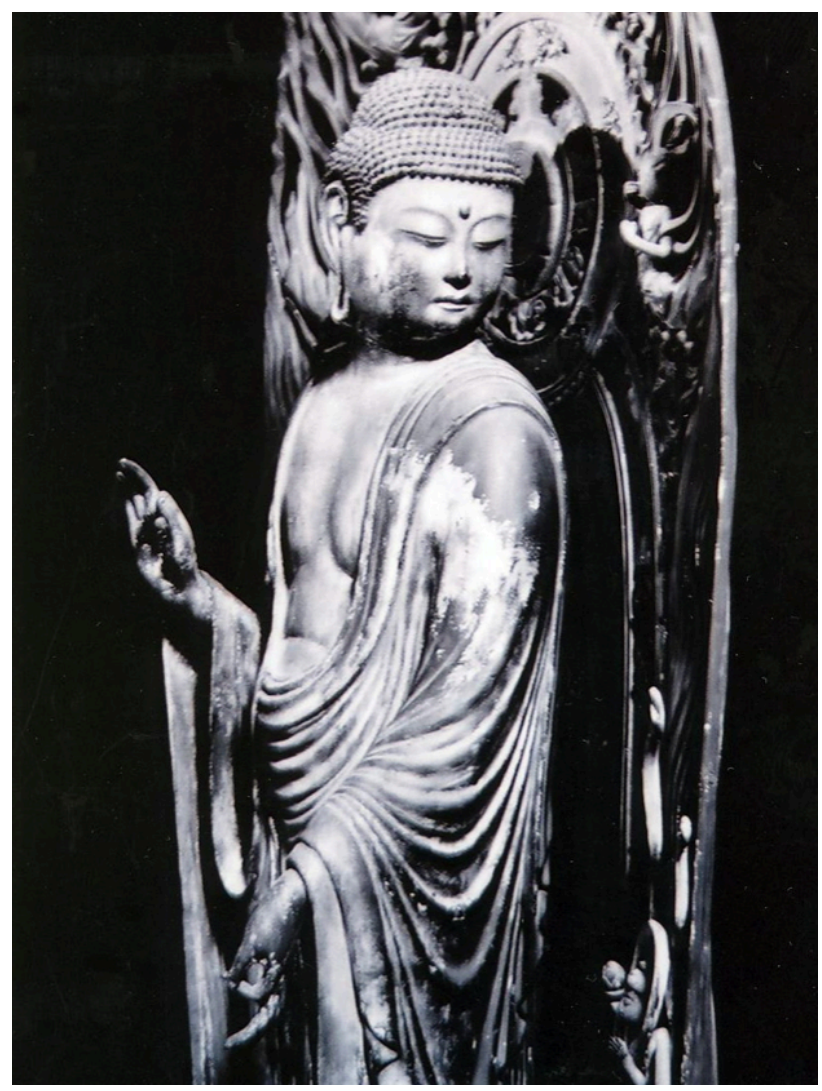

Figure 5: The Mikaeri Amida (Amitabha Looking Back) deity at Zenrin-Ji in Kyoto

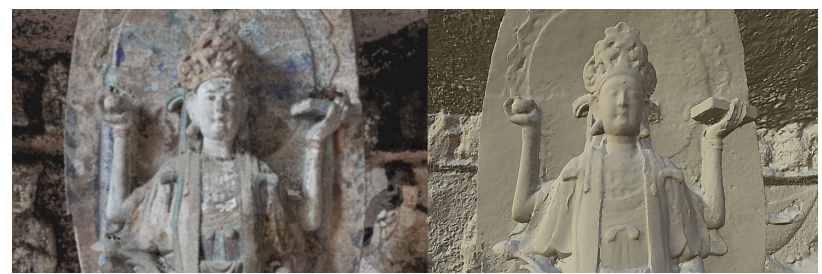

Figure 6: Point cloud view (L) and low-polygonal view of Peacock Radiant Wisdom King at Cave No.8 in Shemenshan, Dazu Rock Carving.

For Bodhisattva, initially, it is depicted as the male figure in India and earlier deities, such as Gandhara-style Bodhisattva in 2nd Century. [Figure 7] In China, the female figures to show the compassion become famous after Tang Dynasty. At Dazu Rock Carvings, the elegance and exquisiteness are frequently witnessed among the majority of the Bodhisattva Deities. One particular deity of Song Dynasty (960-1127 A.D.) with the unique expression - the Counting Beads Avalokiteśvara (aka Charming Avalokiteśvara) - becomes the highlight of Beishan area at the Niche No. 125 [Figure 8]:

\footnotetext{
${ }^{1}$ Introduction of Mikaei Amida at Eikando.

${ }^{2}$ P.36, Dazu Rock Carvings.
} 


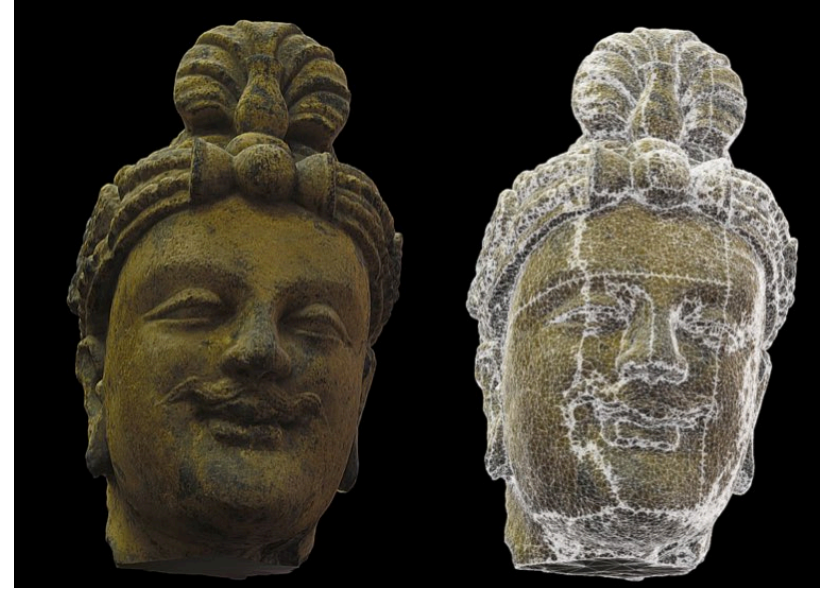

Figure 7: Gilt grey schist Bodhisattva from the ancient region of Gandhara circa 2nd - 3rd Century, H $15.5 \mathrm{~cm}$. Cyber Archive by photogrammetry.

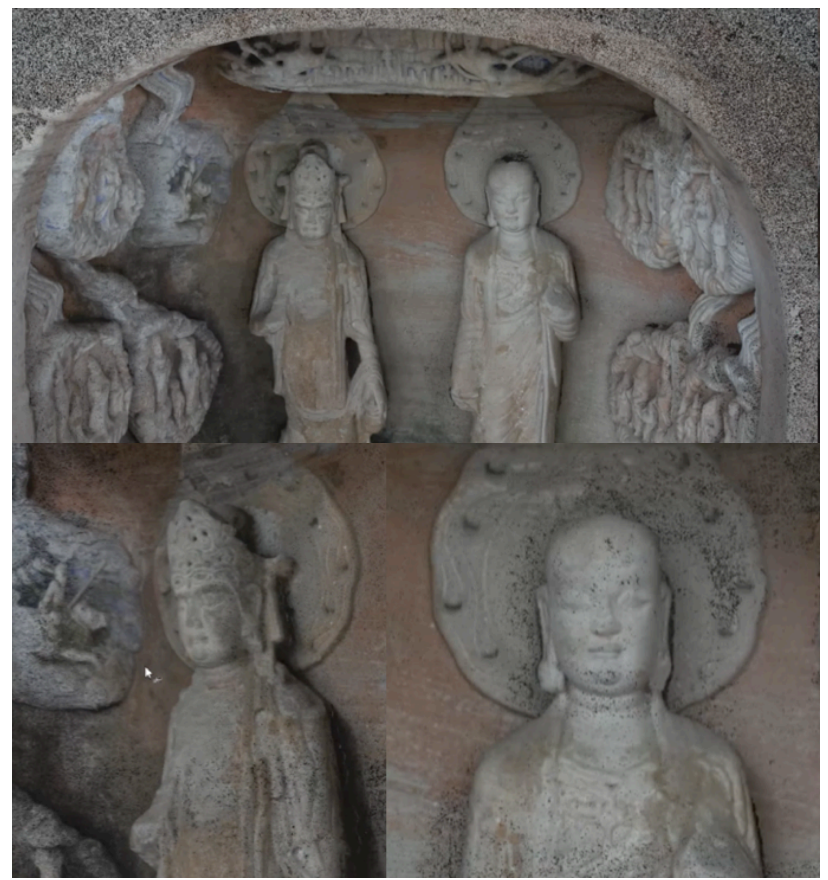

Figure 8: Expressions, gestures and full view of the niche No. 125 "Charming Avalokteśvara" deity. $92 \mathrm{~cm}$ in height. Point cloud visualization.

"This Avalokiteśvara is counting the beads with the right hand that is gently held by the left hand at the wrist. The belts of her dress are waving in the wind just as those beautifully painted by the famous painter Wu Daozi. Like a graceful and shy maiden, she turns her head a little to the left, and watches down with a smile." $\left[{ }^{3}\right]$ Regarding the origin of Charming Avalokiteśvara, the author believes it is Sri-Mahadevi compared to the iconography portrayed in Hinduism of India and Esoteric Buddhism in Japan. Even though in the official publication from Dazu Rock Carvings, the deity is categorized as the Avalokiteśvara. The shy, innocent expression and gesture of Charming Avalokiteśvara, different from the gentle, merciful looks of the other Count Beads Avalokiteśvara deities at Dazu Rock Carvings, convey the young and refreshing energy to the viewers and further enhances the belief in looking for prosperity, auspiciousness, and mindfulness.

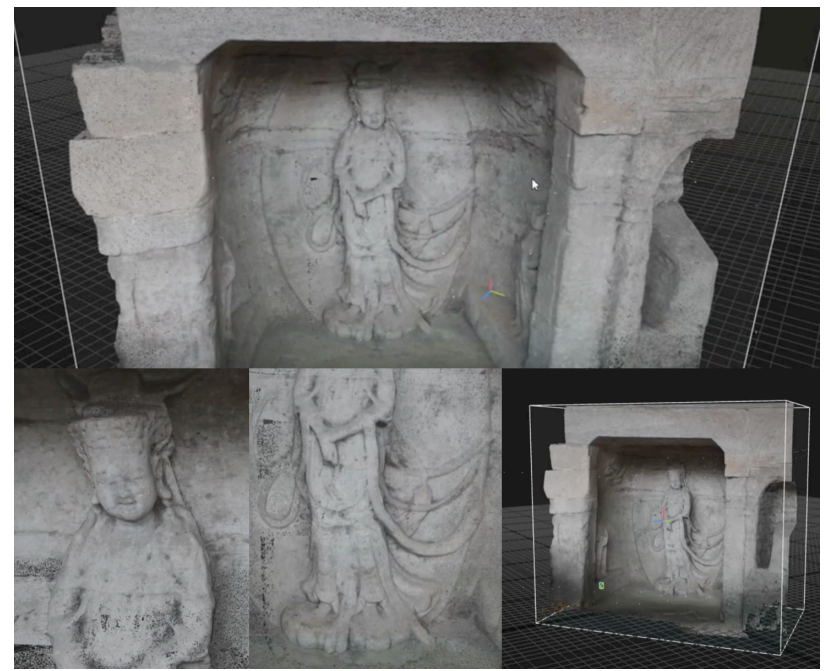

Figure 9: Niche No.253 "Bodhisattva and Ksitigarbha" deities. Point cloud visualization.

\section{Digital humanity in cultural heritage conservation}

Softwares nowadays provide easy access to digitally sculpting or documenting the physical objects. Digital sculpting depends on the artist's sense, techniques, and experiences towards the anatomic precision, form, balance, and motion. Sculptors' movements further extend to performance, then transforms into motion sculptures...etc., like never-ending echoes. Compared to digital sculpting, digital documentation rationally and precisely conserves the digital data, analyze the complex forms or damaged parts, and rebuild the real subjects in the virtual world, such as photogrammetry or laser scanning. These documentation methods are widely adopted and with easier solutions simply by mobile phone cameras and software.

Back in the days when the Virtual World Heritage Laboratory led the Digital Sculpture Project (2009-2013), it focused on the complexity of famous sculptures and utilizes $3 \mathrm{~d}$ laser scanning to restore the point cloud data from the sculptures. The project's attention to the "neglected area of the digital humanities" and cultural significance, shows the uniqueness of the Digital Sculpture Project. The selected sculptures, ranging from Alexander to Laocoön, inherit the richness of form and context. Digital documentation of sculptures, through the earlier efforts, integrates into heritage preservation and consistently applies to heritage information projects.

Technically speaking, BAE project integrates the computer graphics and interactive info-motion design, virtual reality and CAVE as the forms to explore the meaning and metamorphosis of the Sutra. Selected niches and caves at Dazu Rock Carvings (e.g., Bodhisattva, Ksitigarbha, Peacock Radiant Wisdom King) are documented by hybrid scanning (photogrammetry/laser scanning/UAV data). Raw data is analyzed and re-established digitally by reality capture software. Point cloud data (.asc/.xyz/.ply) as the initial results can be further interpreted by modeling, texturing and rendering. Compared with the existing projects of cave art and cultural heritage, BAE project utilizes hybrid techniques in the cyber-archiving process for balancing the accuracy and visibility.

\footnotetext{
${ }^{3}$ P.51, Dazu Rock Carvings.
} 
Digital humanity is the first priority in BAE project facilitated by the dialogues between the contexts and science. BAE project selects digital heritage as the form to study Dazu Rock Carvings to explore the tangible and intangible values of digital humanity. The intangible aspect of the project will be investigated, including the cultural meaning, interconnections between deities depicted, analysis of the iconography, accentuation of the dynamism of time and change, and narration in the new digital space afforded now.

Buddhism and its path from India, Dun Huang to Japan symbolize the dissemination of intercultural activities along the Silk Road. Dazu District and Sichuan, on the other hand, connects with Dun Huang and Japan by the cave art, religion, and culture. The existence of Dazu Rock Carvings and its preservation symbolizes the echoes of both the digital and social humanities.

\section{PROJECT PLAN AND LONG-TERM SUSTAINABILITY}

BAE project will focus on the abundant and exquisite rock carving sites which is widely spread at Dazu District and surrounding areas (more than 500 niches/caves and over 10,000 rock-carvings) in Sichuan province ever since Tang dynasty in China.

BAE project values the most of the conservation of cultural heritage, and proposes developing digital heritage contents to preserve the physical objects and sites. Digital data documented and archived from the cultural objects and heritages sites can be further disseminated through publishing, exhibitions, symposium presentations, websites and social media. The experience and knowledge obtained from BAE project can also be simplified and transformed into contents for primary secondary school education, such as STEM education materials.

As the Vajracchedika-Prajna-Paramita Sutra (Diamond Sutra) frequently addresses in the text:

"if a Bodhisattva (still) clings to the false notion (laksana) of an ego, a personality, a being and a life, he is not ( a true) Bodhisattva."

The various looks of those deities in the caves and niches inevitably get corrosion and surface weathering even human destructions throughout the years. As the sentient beings in the world, our empathies on all the happenings and wishing to preserve the cultural heritage are universal. Through the digitization process of cyber-archiving, hopefully, the echoes of the ancient teachings to be heard and pass on.

\section{ACKNOWLEDGMENTS}

Sincere gratitude to Dazu Rock Carvings Institute and Professor Chen Ching Xiang of Chinese Culture University.

\section{REFERENCES}

Bringing the Ancient Theater of the Silk Road to Los Angeles. East West Bank. https://www.eastwestbank.com/ReachFurther/ News/Article/Bringing-the-Ancient-Theater-of-the-Silk-Roadto-Los-Angeles

Cultural Heritage Conservation in Pakistan: Conversation with Dr Richard A. Engelhardt. https://www.youtube.com/watch? $\mathrm{v}=\mathrm{BWYUO0}$ nciss
Dazu Rock Carving Institute. Dazu Rock Carving. Chongqing Publishing Group. Chongqing, China, 2010, 36, 51.

Introduction of Mikaei Amida. http://www.eikando.or.jp/ English/mikaeri_amida_e.html

Jansen, Michael. "Virtual reality for a physical reconstruction? The Bamiyan Buddhas in Afghanistan". Archaeologising Heritage. Panel 3: The Virtualisation of Archaeological Heritage. International Workshop on Angkor / Cambodia. Heidelberg, Germany, 2010.

Kibi Conservation Studio for Cultural Objects. http:// www.kibibunn.info/

Liang Yong, Wu. LOOKING FORWARD TO ARCHITECTURE OF THE NEW MILLENNIUM. http:// newurbanquestion. ifou.org/proceedings/ $1 \% 20 \mathrm{The} \% 20 \mathrm{New} \% 20 \mathrm{Urban} \% 20 \mathrm{Question/}$ Wu\%20Liangyong.pdf

Opening ceremony of "The Cave Temples of Dunhuang, Buddhist Art on China's Silk Road. http://www.yucolab.com/ news/108-opening-ceremony-of-the-at-the-j-paul-gettymuseum-la.html\#.V_R4u2V6yGk

Gandhara - Das buddhistische Erbe Pakistans. https:// www.youtube.com/watch? $v=$ Su2 $z$ CRIMFv8

The Digital Sculpture Project. Virtual World Heritage Laboratory. http://www.digitalsculpture.org

The International Dunhuang Project. http://idp.bl.uk/idp.a4d The Vajracchedika-prajna-paramita Sutra. http://big5.xuefo.net/ $\mathrm{nr} /$ article $1 / 7446 . \mathrm{html}$

重慶大足石刻藝術博物館. 大足石刻研究文集第四輯. 中國 文聯出版社. 北京, 中國 : 2002 .

牧野隆夫. 仏像再興 仏像修復をめぐる日々. 山と渓谷社出 版. Yama-kei Publishers co., Ltd. Tokyo, Japan: 2016.

笽内佐斗司. 壞れた仏像の声を聴く- 文化財の保存と修復. 角川学芸出版. KADOKAWA Publishing. Tokyo, Japan: 2015. 